\title{
Reversible Cardiomyopathy Complicating Intrathecal Baclofen Withdrawal: A Case Report
}

\author{
Anthony F. Pizon, MDa , Frank LoVecchio, DO, MPH \\ aUniversity of Pittsburgh School of Medicine, Division of Medical Toxicology, Pittsburgh, PA \\ bBanner Good Samaritan Medical Center, Department of Medical Toxicology, Phoenix, AZ
}

\begin{abstract}
This case report is about reversible cardiomyopathy associated with intrathecal baclofen withdrawal. Previous literature has reported that enteral baclofen does not adequately control intrathecal baclofen withdrawal. In our case, coronary atherosclerosis did not play a role in the development of the cardiomyopathy. However, reinstitution of intrathecal baclofen promptly resulted in improvement. One could hypothesize that myocardial stunning from sympathetic hyperactivity led to a similar cardiomyopathy reported with catecholamine excess or acute sympathomimetic poisoning.
\end{abstract}

\section{INTRODUCTION}

Baclofen is a gamma-aminobutyric acid (GABA) agonist frequently used as an intrathecal infusion to treat muscle spasticity. Baclofen withdrawal is life-threatening and can include seizures, autonomic instability, hyperthermia, rigidity, encephalopathy, and multi-system organ failure. Acute cardiomyopathy from baclofen withdrawal has not been adequately described in the literature [1]. We are presenting a case of intrathecal baclofen withdrawal complicated by myocardial stunning and requiring intra-aortic balloon pump therapy. The case resulted in complete recovery.

\section{CASE REPORT}

A 45-year-old C6 quadriplegic man had received intrathecal baclofen for several years and developed a perceived side-effect, and he was slowly weaned from the intrathecal baclofen over four months. The patient had a history of chronic back pain and secretion of inappropriate antidiuretic hormone (SIADH). In addition to the intrathecal baclofen, he was prescribed zonisamide, gabapentin, olanzapine, and tegaserod. The patient had been chronically taking these medications without dose adjustment during the baclofen wean. The family was unaware of any history of illicit drug or ethanol abuse.

Within 12 hours of complete cessation of the intrathecal baclofen, he suffered pruritis, spasticity, fever, and fatigue. Family found him in his apartment, and he was presented 40 hours after baclofen discontinuation in a coma and respiratory failure. Presenting vital signs included tachycardia (160 beats per min), hyperpyrexia $\left(106.4^{\circ} \mathrm{F}\right)$, and labile blood pressure (ranging from $130 / 50$ to $88 / 36 \mathrm{mmHg}$ ). He also had diaphoresis, mottled skin, and diffuse muscle rigidity. He was intubated for airway protection and a post-intubation chest $\mathrm{x}$-ray demonstrated a right lower lobe infiltrate in which gatifloxicin was initiated. Remaining laboratory studies were unrevealing: electrolytes, BUN, creatinine, complete blood count, prothrombin time, liver function tests and thyroid function tests. Only benzodiazepines were identified in a urine drug screen which was suspected to be the result of iatrogenic administration during oral intubation.

Keywords: baclofen withdrawal, cardiomyopathy, intrathecal

Notes: There was no outside funding of any kind used for this study. Poster Presentation at the 2005 North American Congress of Clinical Toxicology Annual Meeting, Orlando, FL.

Corresponding Author: Anthony F. Pizon, MD, Division of Medical Toxicology, UPMC Presbyterian, 200 Lothrop Street, Suite DL-45, Pittsburgh, PA 15213. Email: pizonaf@upmc.edu 
Over the next 20 hours, intravenous lorazepam (38 mg total dose), nasogastric baclofen (120 mg total dose), and a continuous infusion of propofol (as high as $55 \mathrm{mcg} / \mathrm{kg} / \mathrm{min}$ ) were given to control signs while arrangements were made to reinstitute intrathecal baclofen. Due to a prolonged interhospital transport time, intrathecal baclofen re-instatement was greatly delayed. Approximately 60 hours after stopping the intrathecal administration, but before the baclofen pump was reinstituted, he became consistently hypotensive $(82 / 30 \mathrm{mmHg})$; an ECG showed ST segment elevations in the anterior-lateral leads, and a troponin-I was elevated at $20.3 \mathrm{ng} / \mathrm{ml}$. An emergency cardiac angiogram showed normal coronary arteries and global hypokinesis with an ejection fraction of $10 \%$ and a cardiac index of $1.6 \mathrm{~L} / \mathrm{min} / \mathrm{M}^{2}$. In addition to intravenous norepinephrine and dopamine, an intra-aortic balloon pump was initiated. Seventy-two hours after his baclofen pump was discontinued, $25 \mathrm{mcg}$ of intrathecal baclofen was administered over four hours and an infusion of $22 \mathrm{mcg} / 24$ hours was continued. Over several days his rigidity and hyperthermia resolved, and his mental status normalized. We discontinued the intra-aortic balloon pump on hospital day 3 and vasopressors were stopped on hospital day 5. After 11 days of reinstituting intrathecal baclofen, an echocardiogram demonstrated an ejection fraction of 50-55\% and was without valve dysfunction.

Though he was maintained on antibiotics at different times during his hospital stay, there was no growth in initial cultures taken from his sputum, blood, and urine.

\section{DISCUSSION}

The temporal relationship with intrathecal baclofen discontinuation and the onset of the patient's symptoms makes baclofen withdrawal the most likely cause of his syndrome. Additionally, collaborating laboratory findings makes other diagnoses, such as sepsis, thyrotoxicosis, and sympathomimetic abuse, less likely. We excluded other diagnosis such as neuroleptic malignant and serotonin syndromes, on the basis of another more likely etiology-baclofen withdrawal. The focal pulmonary infiltrate was more likely the result of rather than the cause of the patient's presenting signs. Right lower lobe infiltrates are often the result of aspiration pneumonitis in unconscious patients or, less likely, the result of local pulmonary edema from poor cardiac function.

Reversible myocardial stunning from sympathetic hyperactivity has been well-described from sudden emotional stress, acute sympathomimetic poisoning, pheochromocytoma, high-dose epinephrine, and others [2-7]. Moreover, hyperadrenergic states with elevated plasma catecholamine levels after withdrawal from the GABA-agonist, ethanol, have been described as well [8]. Institution of benzodiazepines during the withdrawal syndrome subsequently revealed decreased plasma catecholamine levels and a resolution of symptoms. Baclofen would conceivably cause a similar rise in catecholamines during withdrawal due to a similar mechanism found in ethanol. The main difference between ethanol and baclofen, however, is baclofen primarily effects GABA-B receptors while ethanol affects GABA-A. Clinically, the baclofen withdrawal syndrome is consistent with a hyperadrenergic state like ethanol withdrawal.

In our case, coronary atherosclerosis did not play a role in the development of the cardiomyopathy. However, reinstitution of intrathecal baclofen promptly resulted in improvement. The administration of oral baclofen replacement and intravenous benzodiazepines may be inadequate treatment due to the much lowered intrathecal levels obtained [9]. Supportive care allowed for a reasonable time of recovery, and treatment of the withdrawal symptoms with re-initiation of intrathecal baclofen could theoretically ameliorate the effects of the hyperadrenergic state centrally.

The pathophysiology for this excess catecholamine-induced cardiomyopathy is still unclear $[2,8]$. The cardiotoxicity is suspected from a possible combination of cellular hypoxia, free radial production, and increased intracellular calcium. The cellular hypoxia may result from epicardial coronary artery vasoconstriction, microvascular occlusion, or possibly both [10,11]. In addition, free radicals formed from monoamine oxidase metabolism of epinephrine have been linked to cardiotoxicity, but follow up studies reported epinephrine levels required to produce significant free radial stress are not physiologic $[12,13]$. Lastly, excessive catecholamine stimulation of $\beta$-receptors leads to intracellular calcium-overload and ATP depletion from calciumdependent phosphatases, but it is unclear if the increased calcium is a result or cause of lost myocyte viability [14]. Several other theories have been proposed, but they are not supported in the literature.

One could hypothesize that myocardial stunning from sympathetic hyperactivity led to the reversible cardiomyopathy seen in this case. Further research is required to clearly work-out the pathophysiology of baclofen withdrawal and catecholamineinduced cardiomyopathy.

The authors have no potential financial conflicts of interest to report.

\section{REFERENCES}

1. Mohammed I, Hussain A. Intrathecal baclofen withdrawal syndrome-a life-threatening complication of baclofen pump: A case report. BMC Clin Pharmacol. 2004; $4: 6$.

2. Wittstein IS, Thiemann DR, Lima JAC, Baughman KL, Schulman SP, Gerstenblith G, Wu KC, Rade JJ, Bivalacqua TJ, Champion HC. Neurohumoral features of myocardial stunning due to sudden emotional stress. N Eng J Med. 2005;352:539-548.

3. Hong R, Matsuyama E, Nur K. Cardiomyopathy associated with the smoking of crystal methamphetamine. JAMA.

1991;265:1152-1154.

4. Jacobs LJ. Reversible dilated cardiomyopathy induced by methamphetamine. Clin Cardiol. 1989;12:725-727.

5. Schifferdecker B, Kodali D, Hausner E, Aragam J. Adrenergic shock - An overlooked clinical entity? Cardiol Rev.

2005; 13: 69-73. 
6. Stewart MJ, Fraser DM, Boon N. Dilated cardiomyopathy associated with chronic overuse of an adrenaline inhaler. $\mathrm{Br}$ Heart J 1992;68:221-222.

7. Haft JI. Cardiovascular injury induced by sympathetic catecholamines. Prog Cardiovasc Dis. 1975;17:73-86.

8. Carlsson C, Haggendal J. Arterial noradrenaline levels after ethanol withdrawal. Lancet. 1967;290:889.

9. Greenberg MI, Hendrickson RG. Baclofen withdrawal following removal of an intrathecal baclofen pump despite oral baclofen replacement. J Toxicol Clin Toxicol. 2003; 41:83-85.

10. Lacy CR, Contrada RJ, Robbins ML, Tannenbaum AK, Moreyra AE, Chelton S, Kostis JB. Coronary vasoconstriction induced by mental stress (simulated public speaking). Am J Cardiol. 1995; 75:503-505.

11. Handforth CP. Isoproterenol-induced myocardial infarction in animals. Arch Pathol. 1962;73:161-165.

12. Singal PK, Yates JC, Beamish RE, Dhalla NS. Influence of reducing agents on adrenochrome-induced changes in the heart. Arch Pathol Lab Med. 1981;105:664-669.

13. Wheatley AM, Thandroyen FT, Opie LH. Catecholamineinduced myocardial cell damage: Catecholamines or adrenochrome. J Mol Cell Cardiol. 1985;17:349-359.

14. Fleckenstein A, Frey M, Fleckenstein-Grun G. Consequences of uncontrolled calcium entry and its prevention with calcium antagonists. Eur Heart J. 1983;4 suppl H:43-50. 